\title{
Outcome and evaluation of prognostic factors after pancreaticoduodenectomy for distal cholangiocarcinoma
}

\author{
Johannes Byrling a, Roland Andersson a, Agata Sasor ${ }^{b}$, Gert Lindella, Daniel Ansaria, Johan Nilssonc, \\ Bodil Andersson ${ }^{\mathrm{a}}$
}

Clinical Sciences Lund, Lund University and Skåne University Hospital, Sweden

\section{Abstract}

\begin{abstract}
Background The aim of the present study was to examine the outcomes and prognostic factors after surgery with curative intent for distal cholangiocarcinoma during a modern timespan, in a Swedish tertiary referral center.
\end{abstract}

Methods All patients who underwent pancreaticoduodenectomy for distal cholangiocarcinoma between April 2008 and December 2015 were identified. Survival was estimated using the KaplanMeier analysis. Demographic, clinical, laboratory and histopathological data were evaluated for prognostic factors relating to mortality, using univariable and multivariable statistical analysis.

Results Fifty-four patients were included. The mean age was $68 \pm 8$ years and 21 (39\%) of the patients were female. Jaundice was present at diagnosis in $73 \%$ of the patients. There was no 90-day mortality. Complications graded as Clavien-Dindo $\geq 3$ occurred in 10 (19\%) of the patients. Twenty-eight (52\%) received adjuvant therapy. Overall survival rates at 1,3 , and 5 years were $80 \%, 21 \%$, and $9.2 \%$, respectively. Median survival was 22.2 months. The presence of lymph node metastases was found to be the only independent predictor of survival (hazard ratio 2.88, $95 \%$ confidence interval 1.22-6.84; $\mathrm{P}=0.016$ ). The total number of lymph node metastases, lymph node ratio or total number of resected nodes did not improve the prediction.

Conclusions We found that the recurrence rate was higher and the survival poorer after surgery for distal cholangiocarcinoma than has previously been reported. Lymph node status at the time of resection was the most important prognostic factor for survival in the current material.

Keywords Distal cholangiocarcinoma, survival, prognostic factor, lymph node metastasis

Ann Gastroenterol 2017; 30 (4): 1-7

\section{Introduction}

Cholangiocarcinoma (CCA) is an epithelial cell malignancy arising along the biliary tree. The current classification, based on anatomical location, defines CCAs as either intrahepatic

Departments of a Surgery, Clinical Sciences Lund, Lund University, and Skåne University Hospital (Johannes Byrling, Roland Andersson, Gert Lindell, Daniel Ansari, Bodil Andersson); ${ }^{\text {PPathology, Clinical Sciences }}$ Lund, Lund University and Skane University Hospital (Agata Sasor); ${ }^{c}$ Cardiothoracic Surgery, Clinical Sciences Lund, Lund University, and Skåne University Hospital (Johan Nilsson), Sweden

Conflict of Interest: None

Correspondence to: Bodil Andersson, MD, PhD, Department of Surgery, Clinical Sciences Lund, Lund University and Skåne University Hospital, Lund, SE-221 85 Lund, Sweden, Tel.: + 46461727 57, e-mail: bodil.andersson@med.lu.se

Received 29 December 2016; accepted 29 May 2017; published online 20 June 2017

DOI: https://doi.org/10.20524/aog.2017.0169
(iCCA) or extrahepatic (eCCA). eCCAs are then further distinguished as either perihilar (pCCA) or distal (dCCA) [1]. dCCA originates between the insertion of the cystic duct and up to but not including the ampulla of Vater $[2,3]$. CCA is a rare malignancy. The incidence of eCCA in western countries varies between $0.5-1.2$ cases per 100,000 inhabitants [4]. However, the incidence is significantly higher in some Asian countries [5].

The overall survival of patients with CCA is low, with 5 -year survival being less than 5\% [6]. Neither radiotherapy nor chemotherapy represents an effective treatment option, and currently the only treatment with curative potential regardless of tumor location is surgery. However, surgery with curative intent is only possible in about one third of the patients [7]. The procedure of choice for dCCA is a pancreaticoduodenectomy (PD) [2]. The evidence for adjuvant treatment with chemotherapy or radiotherapy is inadequate, and current recommendations are primarily based on nonrandomized studies [8]. The rate of recurrence after surgery is high. A meta-analysis of surgical outcomes after resection for dCCA, including 3258 patients operated between 1973 and 2013 , reported that the 5-year survival for dCCA was between 
13-54\% [9]. It was shown that $\mathrm{R} 1$ resection, lymph node metastasis (LNM), perineural invasion, lymphatic invasion, vascular invasion, pancreatic invasion, and pathological tumor stage $\geq \mathrm{T} 3$ were associated with shorter survival [9].

The aim of the present study was to examine the surgical outcomes and prognostic factors for dCCA, during a modern timespan, in a Swedish tertiary referral center [10].

\section{Patients and methods}

The study was approved by the Regional Human Ethics Committee in Lund Sweden.

\section{Patient population}

All consecutive patients undergoing resection for dCCA at the Department of Surgery, Skåne University Hospital, Lund and Malmö, between April 2008 and December 2015, were identified from hospital records, aided by a computer search (International Classification of Disease-10, surgical classification code JLC40). The medical records were reviewed retrospectively. Inclusion criteria were PD with a histopathologically confirmed dCCA. During the study period, Skåne University Hospital served as the referral center for all periampullary malignancies in the south of Sweden (population approximately 1.7 million).

\section{Preoperative biliary drainage (PBD)}

PBD was performed at the patients' local hospital in accordance to local guidelines. At our center it is not performed routinely; however, a majority of patients receive PBD prior to surgery. Endoscopic biliary drainage is considered the primary alternative and percutaneous biliary drainage as a secondary alternative.

\section{Operative procedure}

PD was performed as a partial pancreatectomy with classic resection, including limited distal gastrectomy and standard lymphadenectomy. The reconstruction was performed with a pancreaticogastrostomy, and with gastroenterostomy and hepaticojejunostomy performed on the same jejunal loop [10].

\section{Follow up}

Patients were seen one month after surgery at the outpatient clinic with a clinical examination, and information about the histopathological diagnosis and further treatment options. Adjuvant therapy was administered at the patients' local hospital. Follow up was performed every 6 months for two years and then annually up to five years postoperatively, and included computed tomography and liver enzymes, as well as carbohydrate antigen 19-9 (CA 19-9). Patient follow-up data were acquired through patient records that were reviewed retrospectively. Adjuvant chemotherapy was recorded, as well as the time and location of eventual recurrences. Recurrences and survival status were recorded on the $18^{\text {th }}$ of February 2016. Survival status was determined using the Patient Administrative Support in Skåne (PASIS) database.

\section{Variables included in the survival analysis}

Variables that were considered appropriate for outcome analysis included general clinical information at the time of operation (age, sex, body mass index, history of diabetes, history of smoking, type of preoperative biliary drainage, preoperative cholangitis), and preoperative blood samples (hemoglobin, thrombocytes, leukocytes, aspartate aminotransferase, alanine aminotransferase, alkaline phosphatase, albumin, CA 19-9, C-reactive protein, and total bilirubin). Perioperative factors (operative time, estimated blood loss, blood transfusions during surgery and up to 30 days postoperatively, vascular resection, American Society of Anesthesiologists [ASA] score) [11] and postoperative complications within 30 days of surgery or during the same hospitalization period as the operation) were recorded. For histopathological evaluation, all tumor specimens were retrieved and reexamined in order to obtain a standardized assessment. All specimens were reassessed in accordance with the WHO classification of tumors of the digestive system, $4^{\text {th }}$ edition [12]. The reassessments were made by an experienced gastrointestinal pathologist (AS). Pathological evaluation included tumor size, grading based on the predominant morphological pattern (low/moderate/high differentiation), presence of LNM, total number of lymph nodes examined, lymph node ratio (LNR), perineural invasion, microvascular invasion, lymphatic invasion, pancreatic invasion and peripancreatic fat invasion. In three patients we were unable to retrieve material for reevaluation and available data were collected from the initial pathological records. Assessment of radical resection was based on the initial pathology records, as available material did not allow for reassessment of the resection margins.

\section{Study definitions}

The level of complications was graded according to the Clavien-Dindo system [13]. Post-pancreatectomy hemorrhage, and delayed gastric emptying were graded A-C in accordance with the International Study Group of Pancreatic Surgery (ISGPS) definitions [14,15]. Postoperative pancreatic fistula was graded B-C in accordance with the updated ISGPS criteria [16]. Tumor staging was based on the American Joint Committee on Cancer (AJCC) Cancer Staging Manual, $7^{\text {th }}$ edition [3]. The definition for R0 resection was $\geq 1 \mathrm{~mm}$ from cancer growth. The CA 19-9 was dichotomized at $35 \mathrm{kE} / \mathrm{L}$, which is the upper limit of the normal reference interval [17]. LNR is the number of positive nodes/total number of resected 
nodes. We choose to employ a LNR cutoff of 0.17 , as has been reported previously [18].

\section{Statistical analysis}

Values of continuous variables are given as mean \pm standard deviation or median and interquartile range. For categorical values, absolute numbers and the distribution in percentages on available data are given. The Kaplan-Meier analysis was used to estimate long-term survival. Differences in survival were analyzed using a univariable Cox proportional hazards regression $(\mathrm{CPH})$ model. Variables with a P-value $<0.2$ from the univariable analyses were included in the multivariable analysis. A CPH model, with stepwise backward selection (removal limits of $\mathrm{P}<0.100$ ), was used to identify independent predictors of survival. To determine the optimal measurement of LNM (presence/absence of LNM, total number of LNM, total number of resected lymph nodes or cutoff LNR of 0.17 ) for discriminating survival, $\chi^{2}$ scores, calculated using the Cox proportional hazards model, were compared. The maximum $\chi^{2}$ score was taken as the optimal model. P-values $<0.05$ were considered significant. Hazard ratios (HRs) are presented with 95\% confidence intervals (CI). Statistical analysis was performed with Stata MP statistical package version 14.2, 2016 (Stata Corporation, College Station, Texas, USA).

\section{Results}

A total of 54 patients, 33 men and 21 women, fulfilled the inclusion criteria. The patients were between 53 and 85 years old with a mean of $68 \pm 7.7$ years at the time of surgery. Most patients had ASA score II 27 (50\%) or III 22 (41\%) preoperatively. The following symptoms were present upon presentation: Jaundice 39 (72\%), abdominal pain 19 (35\%), weight loss $10(19 \%)$, nausea/vomiting 6 (11\%), while no patient had fever upon presentation (Table 1).

The most common postoperative complications were delayed gastric emptying, with 9 (17\%) having grade B or C, wound infection, deep abdominal infection, postoperative pancreatic fistula, and cholangitis (Table 2). According to the Clavien-Dindo classification, $17(31 \%)$ had a grade I complication, 20 (37\%) grade II, 4 (7.2\%) grade IIIa, 1 (1.9\%) grade IIIb, 3 (5.6\%) grade IVa and 1 (1.9\%) grade IVb (Table 2). Reoperation was performed in 1 patient because of ileus. One patient with abdominal bleeding underwent angiographic coiling of the superior mesenteric artery. There was no 90-day mortality. The average hospital stay was 16.5 days.

The histopathological examination revealed LNM in $39(72 \%)$ patients. The tumor was classified as poorly differentiated in 43 (80\%) samples. Thirty-four (63\%) patients had R1-resections. When staged in accordance with AJCC $7^{\text {th }}$ edition, 15 tumors $(28 \%)$ were stage IIa, 38 (70\%) were stage IIb and 1 (1.9\%) was stage III (Table 3$)$.

Twenty-eight patients (52\%) received adjuvant therapy (3 cycles or more completed). The most common regime was 6 cycles of gemcitabine; however, 4 patients received adjuvant
Table 1 Preoperative clinicopathological data for patients with distal cholangiocarcinoma

\begin{tabular}{lll}
\hline Variable $\quad \mathrm{N}$ & $\begin{array}{l}\mathrm{n}(\%), \operatorname{mean} \pm \mathrm{SD} \\
\text { or median (IQR) }\end{array}$
\end{tabular}

\begin{tabular}{|c|c|c|}
\hline \multicolumn{3}{|l|}{ Clinical data } \\
\hline Age (years) & 54 & $68 \pm 7.7$ \\
\hline Female sex & 54 & $21(39 \%)$ \\
\hline $\operatorname{BMI}\left(\mathrm{kg} / \mathrm{m}^{2}\right)$ & 54 & $25 \pm 3.5$ \\
\hline Diabetes & 54 & $15(28 \%)$ \\
\hline Smoking & 50 & $20(40 \%)$ \\
\hline PBD & 54 & $53(98 \%)$ \\
\hline ERCP-guided drain & 54 & $48(89 \%)$ \\
\hline PTC-guided drain & 54 & $5(9 \%)$ \\
\hline Preoperative cholangitis & 54 & $14(26 \%)$ \\
\hline \multicolumn{3}{|l|}{ Symptoms at presentation } \\
\hline Jaundice & 54 & $39(72 \%)$ \\
\hline Abdominal pain & 54 & $19(35 \%)$ \\
\hline Weight loss & 54 & $10(19 \%)$ \\
\hline Nausea/vomiting & 54 & $6(11 \%)$ \\
\hline \multicolumn{3}{|l|}{ Preoperative laboratory status } \\
\hline $\mathrm{Hb}(\mathrm{g} / \mathrm{L})$ & 54 & $128(120-138)$ \\
\hline Leukocyte count $\left(\right.$ cells $\left.\times 10^{9} / \mathrm{L}\right)$ & 54 & $7.8(6-9)$ \\
\hline Thrombocyte count (cells $\times 10^{9} / \mathrm{L}$ ) & 54 & $270(230-341)$ \\
\hline ASAT $(\mu \mathrm{kat} / \mathrm{L})$ & 54 & $0.5(0.4-1.0)$ \\
\hline $\operatorname{ALAT}(\mu \mathrm{kat} / \mathrm{L})$ & 54 & $0.8(0.5-1.2)$ \\
\hline $\operatorname{ALP}(\mu \mathrm{kat} / \mathrm{L})$ & 54 & $2.7(1.7-4.7)$ \\
\hline Albumin $(\mathrm{g} / \mathrm{L})$ & 44 & $34(30-38)$ \\
\hline Bilirubin $(\mu \mathrm{mol} / \mathrm{L})$ & 54 & $18(9-34)$ \\
\hline CRP (mg/L) & 50 & $5.8(2-16)$ \\
\hline CA 19-9 (kE/L) & 50 & $142(54-353)$ \\
\hline
\end{tabular}

$\mathrm{N}$ number of non-missing values. Qualitative data are expressed as n (\%) and quantitative data as mean \pm SD or median (IQR)

ALAT, alanine aminotransferase; ALP, alkaline phosphatase; ASAT, aspartate aminotransferase; BMI, body mass index; CA 19-9, carbohydrate antigen 19-9; CRP, C-reactive protein; ERCP, endoscopic retrograde cholangiopancreatography; $\mathrm{Hb}$, hemoglobin; IQR, interquartile range; $P B D$, preoperative biliary drainage; $P T C$, percutaneous transhepatic cholangiography

capecitabine with concomitant radiotherapy, 1 patient capecitabine as monotherapy and 1 patient 5-fluorouracil/ leucovorin as monotherapy. No difference in survival was seen between patients who received adjuvant therapy and those who did not.

Overall survival rates at 1,3 , and 5 years were $80 \%$ (95\% CI 66-89\%), 21\% (95\% CI 9.5-35\%) and 9.2\% (95\% CI 2.0-23\%), respectively (Fig. 1). Median survival was 22.2 months. After one and three years, recurrence had occurred in 55\% and $82 \%$ of patients, respectively. The median time to recurrence was 13 months. The most common recurrence location was liver 
Table 2 Perioperative data and postoperative complications after pancreaticoduodenectomy for distal cholangiocarcinoma

$$
\begin{gathered}
\mathrm{N} \quad \mathrm{n}(\%), \text { mean } \pm \mathrm{SD} \\
\text { or median } \\
(\mathrm{IQR})
\end{gathered}
$$

\begin{tabular}{|c|c|c|}
\hline \multicolumn{3}{|l|}{ Perioperative variables } \\
\hline $\begin{array}{l}\text { ASA } \\
\text { Score I } \\
\text { Score II } \\
\text { Score III }\end{array}$ & $\begin{array}{l}54 \\
54 \\
54 \\
54\end{array}$ & $\begin{array}{l}5(9.3 \%) \\
27(50 \%) \\
22(41 \%)\end{array}$ \\
\hline Operative time (min) & 54 & $480 \pm 90$ \\
\hline Blood loss & 52 & $550(300-700)$ \\
\hline Blood transfusions & 54 & $26(48 \%)$ \\
\hline Vascular resection & 54 & $5(9.3 \%)$ \\
\hline \multicolumn{3}{|c|}{ Postoperative complications } \\
\hline Wound infection & 54 & $15(28 \%)$ \\
\hline Deep infection & 54 & $12(22 \%)$ \\
\hline \multicolumn{3}{|l|}{$\mathrm{PPH}$} \\
\hline Grade A & 54 & 0 \\
\hline Grade B & 54 & $2(3.7 \%)$ \\
\hline Grade C & 54 & $1(1.9 \%)$ \\
\hline \multicolumn{3}{|l|}{ POPF } \\
\hline Grade B & 54 & $5(9.3 \%)$ \\
\hline Grade C & 54 & $1(1.9 \%)$ \\
\hline \multicolumn{3}{|l|}{ DGE } \\
\hline Grade A & 54 & $12(22 \%)$ \\
\hline Grade B & 54 & $5(9.3 \%)$ \\
\hline Grade C & 54 & $4(7.4 \%)$ \\
\hline Cholangitis & 54 & $4(7.4 \%)$ \\
\hline Multi-organ failure & 54 & $1(1.9 \%)$ \\
\hline Pneumonia & 54 & $2(3.7 \%)$ \\
\hline Ileus & 54 & $2(3.7 \%)$ \\
\hline Air embolus & 54 & $1(1.9 \%)$ \\
\hline \multicolumn{3}{|l|}{ Clavien } \\
\hline Grade I & 54 & $17(31 \%)$ \\
\hline Grade II & 54 & $20(37 \%)$ \\
\hline Grade IIIa & 54 & $4(7.4 \%)$ \\
\hline Grade IIIb & 54 & $1(1.9 \%)$ \\
\hline Grade IVa & 54 & $3(5.6 \%)$ \\
\hline Grade IVb & 54 & $1(1.9 \%)$ \\
\hline
\end{tabular}

$\mathrm{N}$ number of non-missing values. Qualitative data are expressed as $\mathrm{n}(\%)$ and quantitative data as mean \pm SD or median (IQR)

ASA, American society of anesthesiologists; DGE, delayed gastric emptying; IQR, interquartile range; POPF, postoperative pancreatic fistula; $P P H$, postoperative pancreatic hemorrhage

metastasis in 17 (31\%) patients, followed by local recurrence in $13(24 \%)$ patients and lymph node recurrence in $5(9.3 \%)$

\begin{tabular}{|c|c|c|}
\hline Variable & $\mathrm{N}$ & $\begin{array}{l}\mathrm{n}(\%), \operatorname{mean} \pm \mathrm{SD} \\
\text { or median (IQR) }\end{array}$ \\
\hline Tumor size (mm) & 53 & $30 \pm 9.6$ \\
\hline R1-resection & 54 & $34(63 \%)$ \\
\hline Moderate differentiation & 54 & $11(20 \%)$ \\
\hline Low differentiation & 54 & $43(80 \%)$ \\
\hline Lymph node metastasis & 54 & $39(72 \%)$ \\
\hline Number of lymph node metastases & 54 & $1(0-4)$ \\
\hline $\begin{array}{l}\text { Number of surgically removed } \\
\text { nodes }\end{array}$ & 54 & $15(11-21)$ \\
\hline Vascular invasion & 54 & $35(65 \%)$ \\
\hline Perineural invasion & 54 & $46(85 \%)$ \\
\hline Lymphatic invasion & 52 & $40(77 \%)$ \\
\hline Pancreatic invasion & 54 & $52(96 \%)$ \\
\hline Adipose tissue invasion & 53 & $45(85 \%)$ \\
\hline \multicolumn{3}{|l|}{ T-stage } \\
\hline Stage 1 & 54 & $1(1.9 \%)$ \\
\hline Stage 2 & 54 & 0 \\
\hline Stage 3 & 54 & $52(96 \%)$ \\
\hline Stage 4 & 54 & $1(1.9 \%)$ \\
\hline \multicolumn{3}{|l|}{ AJCC } \\
\hline Stage I & 54 & 0 \\
\hline Stage IIa & 54 & $15(28 \%)$ \\
\hline Stage IIb & 54 & $38(70 \%)$ \\
\hline Stage III & 54 & $1(1.9 \%)$ \\
\hline \multicolumn{3}{|l|}{ Recurrence location } \\
\hline Liver & 54 & $17(31 \%)$ \\
\hline Local & 54 & $13(24 \%)$ \\
\hline Lymph node & 54 & $5(9.3 \%)$ \\
\hline Peritoneum & 54 & $4(7.4 \%)$ \\
\hline Lung & 54 & $5(9.3 \%)$ \\
\hline
\end{tabular}
patients (Table 3 ).
Table 3 Histopathological analysis after resection for distal cholangiocarcinoma

$\mathrm{N}$, number of non-missing values. Qualitative data are expressed as n (\%) and quantitative data as mean $\pm \mathrm{SD}$ or median (IQR)

AJCC, American Joint Committee on Cancer; IQR, interquartile range; R1-resection, non-radical resection; T-stage, tumor stage

The presence of LNM and their total number were found to be significantly associated with worse overall survival in the univariable analysis, but no significant association was found for the total number of resected nodes $(\mathrm{P}=0.734)$ or $\mathrm{LNR}$ $(\mathrm{P}=0.148)$. The median survival was 28 months in the lymph node-negative and 21 months in the lymph node-positive group. At 3 years, $47 \%$ of patients were estimated to be alive in the lymph node-negative group and $11 \%$ in the lymph nodepositive group (Table 4).

In the multivariable analysis, using a stepwise approach, the $\chi^{2}$ score was calculated for three prediction models: presence/ 
absence of LNM, total number of LNM, and LNR cutoff 0.17; the models included the other covariates presented in Table 4 . The presence/absence of LNM was identified as the only independent risk factor for worse survival, HR 2.88 (95\% CI 1.22-6.84; $\mathrm{P}=0.016)$, with the highest $\mathrm{CPH} \chi^{2}$ score. Survival after PD for dCCA with and without LNM is presented in Fig. 2.

\section{Discussion}

The only possible cure for patients with dCCA is surgical resection, but the prognosis is dismal. We aimed to identify risk factors and investigate the outcomes after surgery for dCCA, during a modern time period in a tertiary western center. Previous studies were mainly of Asian origin and data were collected over longer time spans, during which changes in diagnostic and operative procedures may have occurred.

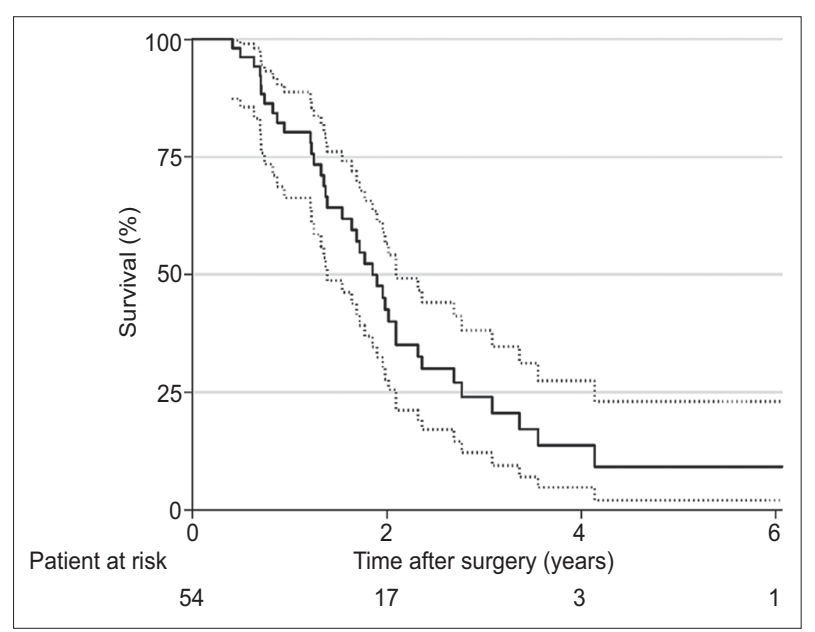

Figure 1 Survival after resection for distal cholangiocarcinoma estimated using the Kaplan-Meier analysis. Survival is presented with 95\% confidence interval

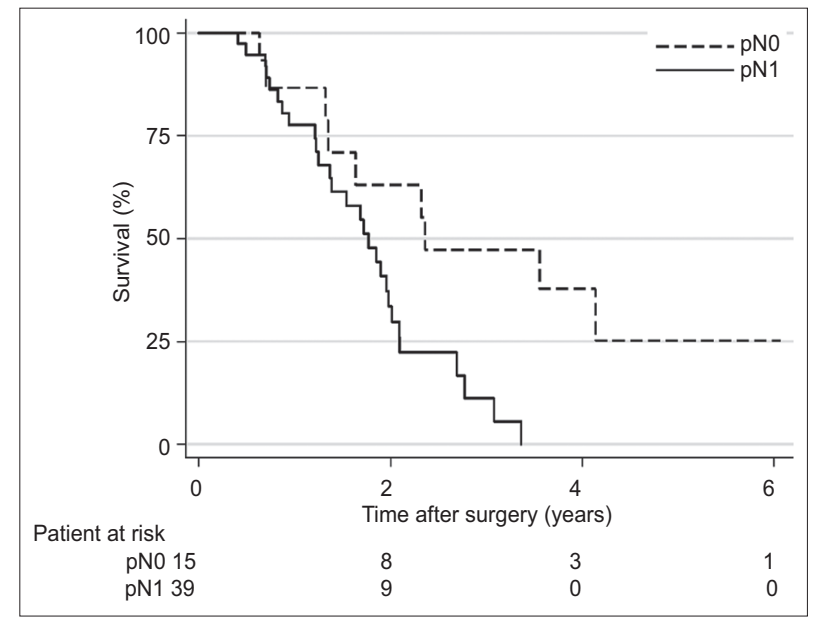

Figure 2 Survival for patients with distal cholangiocarcinoma stratified by presence of lymph node metastasis, estimated using the KaplanMeier analysis
In the present study, a high risk for recurrence after surgery was evident. The median survival was 22.2 months, with an estimated 5 -year survival of $9 \%$. This is a poor outcome compared to previous studies, where 5-year survival ranging between 13-54\% has been reported [9]. Although the results are heterogeneous, several recent larger Asian studies report 5-year survival rates of over $40 \%$ after resection for dCCA [17-19]. In western reports with patient inclusion between 1987 and 2016, the majority of studies report a 5-year survival after surgical resection for dCCA ranging between 18-29\% [20-27], with a few studies reporting even better survival $[28,29]$. The median survival in our study, although still in the lower ranges, is consistent with some previous reports [21,23,25]. Differences in incidence, risk factors and genetic factors that are known to differ between western countries and Asian countries [5,30] could impact the outcome after resection for dCCA. In addition, differences in patient selection could impact differences in outcome, both between and within countries. When comparing our results with those of previous studies, we noted more advanced tumors with a high frequency of risk factors for poor outcome, such as the presence of LNM 72\% versus $22-68 \%[31,32]$, perineural invasion $85 \%$ versus 33 $85 \%$ [27,33], lymphatic invasion $77 \%$ versus $11-81 \%$ [27,33], vascular invasion $65 \%$ versus $7-74 \%[34,35]$, and R1-resection $63 \%$ versus $4-72 \%[36,37]$. These discrepancies could partly be attributed to differences in the histopathological examination of tumor specimens, as well as the definition of R1-resection after PD $[38,39]$. Recently, it has been shown that survival after PD for dCCA and pancreatic ductal adenocarcinoma, to which a worse prognosis has traditionally been attributed, may be similar when matched for variables affecting outcome [20].

We confirmed lymph node status as an important independent risk factor for poor survival in dCCA. Based on

Table 4 Univariable analysis of relevant clinicopathological risk factors after resection for distal cholangiocarcinoma. Variables with $\mathrm{P} \leq 0.2$ that were selected for multivariable analysis are presented

\begin{tabular}{lccc}
\hline Variables & Hazard ratio & $95 \%$ CI & P \\
\hline ASA-score $\geq 3$ & 1.84 & $0.94-3.63$ & 0.077 \\
CRP & 0.98 & $0.97-1.01$ & 0.159 \\
CA $19-9 \geq 35$ & 2.34 & $0.90-6.10$ & 0.081 \\
Lymph node metastasis & 2.88 & $1.22-6.84$ & 0.016 \\
(yes/no) & & & \\
Lymph node ratio $\geq 0.17$ & 1.67 & $0.83-3.35$ & 0.148 \\
$\begin{array}{l}\text { Number of lymph node } \\
\text { metastases }\end{array}$ & 1.08 & $1.01-1.15$ & 0.017 \\
\hline Lymph vessel invasion & 1.93 & $0.84-4.45$ & 0.123 \\
\hline Perineural invasion & 2.30 & $0.70-7.55$ & 0.168 \\
\hline Adipose tissue invasion & 2.54 & $0.88-7.33$ & 0.086 \\
\hline R1-resection & 1.61 & $0.79-3.27$ & 0.186 \\
\hline
\end{tabular}

Differences in survival were analyzed using a univariable Cox-regression model

ASA, American society of anesthesiologists; CA 19-9, carbohydrate antigen 19-9; CRP, C-reactive protein; $R 1$-resection, non-radical resection 


\section{Summary Box}

\section{What is already known:}

- Distal cholangiocarcinoma is a rare malignancy originating between the insertion of the cystic duct and up to but not including the ampulla of Vater

- The only treatment with curative potential is surgery; however, the rate of recurrence is high

- R1 resection, lymph node metastasis, perineural invasion, lymphatic invasion, vascular invasion, pancreatic invasion and pathological tumor stage $\geq \mathrm{T} 3$ have been associated with shorter survival

\section{What the new findings are:}

- We found a 5-year survival of $9 \%$ and a median survival of 22 months after pancreaticoduodenectomy for distal cholangiocarcinoma, which are lower than those reported in most previous studies

- We found the presence of lymph node metastasis to be the only independent risk factor for poor survival

- The total number of lymph node metastases, lymph node ratio and the total number of resected nodes did not improve the prediction

our data, no patient with positive nodal status is expected to be alive after 3.5 years. This finding is in accordance with several previous studies that reported LNM to be an independent risk factor for poor survival in CCA $[17,18,21,25,40]$. We found that the presence of one or more lymph nodes with cancer was a risk factor strongly associated with poor survival. However, the total number of LNM, LNR, and the total number of resected nodes did not improve the prediction. Currently, there is no consensus as to which lymph node variable is most suitable for prognosis in dCCA. Some studies have suggested that the number of positive nodes, with various cutoffs, is superior to binary lymph node status in predicting survival $[18,33,41,42]$. LNR is known to be a superior prognostic tool for several malignancies [43-45]. In dCCA, some studies have suggested LNR could provide additional prognostic value [22,46-48]. Two studies have systematically investigated which variable is the strongest prognostic factor in dCCA. In a large Japanese study $\geq 4$ positive lymph nodes was most strongly associated with survival [18]. A Norwegian study found that binary lymph node status predicted survival, whereas the number of positive nodes and LNR did not provide additional information in node-positive patients with dCCA [25], which is in accordance with our findings. The value of LNR as a prognostic factor can be heavily impacted by differences in lymph node resection and histopathological evaluation strategy, and can thus vary significantly between studies [49].
The strength of the current study is the strict inclusion criteria, where only true dCCAs were included, while pCCAs as well as pancreatic and ampullary tumors were excluded. Furthermore, all the surgical specimens were reevaluated systematically by an experienced gastrointestinal pathologist in order to guarantee the quality. Moreover, the extensive follow up was complete, with no missing cases, and the study duration was limited in order to avoid the impact of changes in clinical treatment, including chemotherapy, over time.

The main limitation of this study is its retrospective design and the low number of patients included. The low number of patients at risk after 5 years makes the estimation of the 5 -year survival uncertain.

In conclusion, we found dCCA to be an aggressive malignancy, with a higher rate of recurrence and mortality after surgical resection compared to previous publications and a survival more similar to pancreatic ductal adenocarcinoma. The presence of LNM is the most important prognostic factor for survival, but measuring the number of LNM, the number of resected nodes, and the LNR does not improve the prediction.

\section{Acknowledgment}

We would like to express our gratitude to senior consultant Robert Szepesvari for assistance in retrieving follow-up data.

\section{References}

1. Nakeeb A, Pitt HA, Sohn TA, et al. Cholangiocarcinoma. A spectrum of intrahepatic, perihilar, and distal tumors. Ann Surg 1996;224:463-473; discussion 473-475.

2. Razumilava N, Gores GJ. Classification, diagnosis, and management of cholangiocarcinoma. Clin Gastroenterol Hepatol 2013;11:13-21.

3. Edge SB, Compton CC, et al. AJCC Cancer Staging Manual. $7^{\text {th }}$. New York, NY: Springer Verlag; 2010.

4. Shaib Y, El-Serag HB. The epidemiology of cholangiocarcinoma. Semin Liver Dis 2004;24:115-125.

5. Bergquist A, von Seth E. Epidemiology of cholangiocarcinoma. Best Pract Res Clin Gastroenterol 2015;29:221-232.

6. Mosconi S, Beretta GD, Labianca R, Zampino MG, Gatta G, Heinemann V. Cholangiocarcinoma. Crit Rev Oncol Hematol 2009;69:259-270.

7. Khan SA, Davidson BR, Goldin RD, et al; British Society of Gastroenterology. Guidelines for the diagnosis and treatment of cholangiocarcinoma: An update. Gut 2012;61:1657-1669.

8. Howell M, Valle JW. The role of adjuvant chemotherapy and radiotherapy for cholangiocarcinoma. Best Pract Res Clin Gastroenterol 2015;29:333-343.

9. Zhou Y, Liu S, Wu L, Wan T. Survival after surgical resection of distal cholangiocarcinoma: A systematic review and meta-analysis of prognostic factors. Asian J Surg 2017;40:129-138.

10. Ansari D, Williamsson C, Tingstedt B, Andersson B, Lindell G, Andersson R. Pancreaticoduodenectomy--the transition from a low- to a high-volume center. Scand J Gastroenterol 2014;49:481-484.

11. Daabiss M. American Society of Anaesthesiologists physical status classification. Indian J Anaesth 2011;55:111-115. 
12. Berglund G, Nilsson P, Eriksson KF, et al. Long-term outcome of the Malmö preventive project: Mortality and cardiovascular morbidity. J Intern Med 2000;247:19-29.

13. Dindo D, Demartines N, Clavien PA. Classification of surgical complications: A new proposal with evaluation in a cohort of 6336 patients and results of a survey. Ann Surg 2004;240:205-213.

14. Wente MN, Bassi C, Dervenis C, et al. Delayed gastric emptying (DGE) after pancreatic surgery: A suggested definition by the International Study Group of Pancreatic Surgery (ISGPS). Surgery 2007;142:761-768.

15. Wente MN, Veit JA, Bassi C, et al. Postpancreatectomy hemorrhage (PPH): An International Study Group of Pancreatic Surgery (ISGPS) definition. Surgery 2007;142:20-25.

16. Bassi C, Marchegiani G, Dervenis C, et al; International Study Group on Pancreatic Surgery (ISGPS). The 2016 update of the International Study Group (ISGPS) definition and grading of postoperative pancreatic fistula: 11 Years After. Surgery 2017;161:584-591.

17. Chung YJ, Choi DW, Choi SH, Heo JS, Kim DH. Prognostic factors following surgical resection of distal bile duct cancer. J Korean Surg Soc 2013;85:212-218.

18. Kiriyama M, Ebata T, Aoba T, et al; Nagoya Surgical Oncology Group. Prognostic impact of lymph node metastasis in distal cholangiocarcinoma. Br J Surg 2015;102:399-406.

19. Ishihara S, Horiguchi A, Miyakawa S, Endo I, Miyazaki M, Takada T. Biliary tract cancer registry in Japan from 2008 to 2013. J Hepatobiliary Pancreat Sci 2016;23:149-157.

20. Courtin-Tanguy L, Rayar M, Bergeat D, et al. The true prognosis of resected distal cholangiocarcinoma. J Surg Oncol 2016;113:575-580.

21. Wiltberger G, Krenzien F, Benzing C, et al. Prognostic accuracy of the seventh edition of the TNM classification compared with the fifth and sixth edition for distal cholangiocarcinoma. Ann Surg Oncol 2016;23:1320-1326.

22. Tol JA, Brosens LA, van Dieren S, et al. Impact of lymph node ratio on survival in patients with pancreatic and periampullary cancer. Br J Surg 2015;102:237-245.

23. Ercolani G, Dazzi A, Giovinazzo F, et al. Intrahepatic, peri-hilar and distal cholangiocarcinoma: Three different locations of the same tumor or three different tumors? Eur J Surg Oncol 2015;41:1162-1169.

24. AndrianelloS, Paiella S, Allegrini V, et al. Pancreaticoduodenectomy for distal cholangiocarcinoma: Surgical results, prognostic factors, and long-term follow-up. Langenbecks Arch Surg 2015;400:623-628.

25. Pomianowska E, Westgaard A, Mathisen $\varnothing$, Clausen OP, Gladhaug IP. Prognostic relevance of number and ratio of metastatic lymph nodes in resected pancreatic, ampullary, and distal bile duct carcinomas. Ann Surg Oncol 2013;20:233-241.

26. van der Gaag NA, Kloek JJ, de Bakker JK, et al. Survival analysis and prognostic nomogram for patients undergoing resection of extrahepatic cholangiocarcinoma. Ann Oncol 2012;23:2642-2649.

27. Hatzaras I, George N, Muscarella P, Melvin WS, Ellison EC, Bloomston M. Predictors of survival in periampullary cancers following pancreaticoduodenectomy. Ann Surg Oncol 2010;17:991-997.

28. van Roest MH, Gouw AS, Peeters PM, et al. Results of pancreaticoduodenectomy in patients with periampullary adenocarcinoma: Perineural growth more important prognostic factor than tumor localization. Ann Surg 2008;248:97-103.

29. Allen PJ, Reiner AS, Gonen M, et al. Extrahepatic cholangiocarcinoma: A comparison of patients with resected proximal and distal lesions. HPB (Oxford) 2008;10:341-346.

30. Banales JM, Cardinale V, Carpino G, et al. Expert consensus document: Cholangiocarcinoma: Current knowledge and future perspectives consensus statement from the European Network for the Study of Cholangiocarcinoma (ENS-CCA). Nat Rev
Gastroenterol Hepatol 2016;13:261-280.

31. Cheng Q, Luo X, Zhang B, Jiang X, Yi B, Wu M. Distal bile duct carcinoma: Prognostic factors after curative surgery. A series of 112 cases. Ann Surg Oncol 2007;14:1212-1219.

32. Bahra M, Jacob D, Langrehr JM, Neumann UP, Neuhaus P. Carcinoma of the distal and middle bile duct: Surgical results, prognostic factors, and long-term follow-up. $J$ Hepatobiliary Pancreat Surg 2008; 15:501-507.

33. Yoshida T, Matsumoto T, Sasaki A, Morii Y, Aramaki M, Kitano S. Prognostic factors after pancreatoduodenectomy with extended lymphadenectomy for distal bile duct cancer. Arch Surg 2002;137:69-73.

34. Woo SM, Ryu JK, Lee SH, et al. Recurrence and prognostic factors of ampullary carcinoma after radical resection: Comparison with distal extrahepatic cholangiocarcinoma. Ann Surg Oncol 2007;14:3195-3201.

35. Hong SM, Pawlik TM, Cho H, et al. Depth of tumor invasion better predicts prognosis than the current American Joint Committee on Cancer T classification for distal bile duct carcinoma. Surgery 2009;146:250-257.

36. Zerbi A, Balzano G, Leone BE, Angeli E, Veronesi P, Di Carlo V. Clinical presentation, diagnosis and survival of resected distal bile duct cancer. Dig Surg 1998;15:410-416.

37. Menon KV, Gomez D, Smith AM, Anthoney A, Verbeke CS. Impact of margin status on survival following pancreatoduodenectomy for cancer: The Leeds Pathology Protocol (LEEPP). HPB (Oxford) 2009;11:18-24.

38. Verbeke CS, Gladhaug IP. Resection margin involvement and tumour origin in pancreatic head cancer. Br J Surg 2012;99:1036-1049.

39. Verbeke CS, Leitch D, Menon KV, McMahon MJ, Guillou PJ, Anthoney A. Redefining the R1 resection in pancreatic cancer. $\mathrm{Br} \mathrm{J}$ Surg 2006;93:1232-1237.

40. Murakami Y, Uemura K, Hayashidani Y, et al. Prognostic significance of lymph node metastasis and surgical margin status for distal cholangiocarcinoma. J Surg Oncol 2007;95:207-212.

41. Hong SM, Cho H, Lee OJ, Ro JY. The number of metastatic lymph nodes in extrahepatic bile duct carcinoma as a prognostic factor. Am J Surg Pathol 2005;29:1177-1183.

42. Murakami Y, Uemura K, Hayashidani Y, Sudo T, Ohge H, Sueda T. Pancreatoduodenectomy for distal cholangiocarcinoma: Prognostic impact of lymph node metastasis. World J Surg 2007;31:337-342.

43. Ozawa T, Ishihara S, Nishikawa T, et al. Prognostic significance of the lymph node ratio in stage IV colorectal cancer patients who have undergone curative resection. Ann Surg Oncol 2015;22:1513-1519.

44. Liao GS, Chou YC, Golshan M, et al. Prognostic value of the lymph node ratio in breast cancer subtypes. Am J Surg 2015;210:749-754.

45. Ke B, Song XN, Liu N, Zhang RP, Wang CL, Liang H. Prognostic value of the lymph node ratio in stage III gastric cancer patients undergoing radical resection. PLoS One 2014;9:e96455.

46. Kawai M, Tani M, Kobayashi Y, et al. The ratio between metastatic and examined lymph nodes is an independent prognostic factor for patients with resectable middle and distal bile duct carcinoma. Am J Surg 2010;199:447-452.

47. Oshiro Y, Sasaki R, Kobayashi A, et al. Prognostic relevance of the lymph node ratio in surgical patients with extrahepatic cholangiocarcinoma. Eur J Surg Oncol 2011;37:60-64.

48. Hurtuk MG, Hughes C, Shoup M, Aranha GV. Does lymph node ratio impact survival in resected periampullary malignancies? Am J Surg 2009; 197:348-352.

49. Shimomura M, Ikeda S, Takakura Y, et al. Adequate lymph node examination is essential to ensure the prognostic value of the lymph node ratio in patients with stage III colorectal cancer. Surg Today 2011;41:1370-1379. 